\title{
Jaccoud arthropathy in a patient with rhupus
}

\author{
Sadettin Uslu ${ }^{1}$ (D) Tuba Yuce Inel ${ }^{2} \cdot$ Çiğdem Samur Salbaş ${ }^{3}$
}

Received: 14 June 2020 / Revised: 14 June 2020 / Accepted: 4 August 2020 / Published online: 21 August 2020

(C) International League of Associations for Rheumatology (ILAR) 2020

\section{Presentation}

A 30-year-old woman was referred to our rheumatology unit with the diagnosis of rhupus. She had a treatment compliance problem and did not use any medication for about 10 years after pregnancy. Physical examination revealed tenderness in the metacarpophalangeal joints, reducible Z-deformities of her thumbs, and swan neck deformities of her fingers (Fig. 1a). XRay of both the hands showed flexion deformities at the metacarpophalangeal and distal interphalangeal joints and a hyperextension deformity at the proximal interphalangeal joints (Fig. 1b). Computerized tomography (CT) of the hands documented cortical erosions and multiple subchondral degenerative cystic alterations of the carpal bones (Fig. 1c). Her erythrocyte sedimentation rate $(56 \mathrm{~mm} / \mathrm{h})$ and C-reactive protein level $(12.7$ $\mathrm{mg} / \mathrm{L}$ ) were elevated. Autoimmune serology showed a strongly positive ANA (1:640, homogeneous pattern), positive antidsDNA (55 IU/mL), and negative extractable nuclear antigens. Complements were also normal. Both rheumatoid factor (RF) $(137.4 \mathrm{IU} / \mathrm{mL})$ and anti-cyclic citrullinated peptide antibody $(110 \mathrm{U} / \mathrm{mL})$ tests were positive.

\section{Discussion}

Jaccoud's arthropathy (JA), a correctable deformity, was originally described in cases with rheumatic fever, but is mainly seen in patients with systemic lupus erythematosus [1]. Furthermore, JA may be associated with Sjogren's syndrome, dermatomyositis, scleroderma, sarcoidosis, HIV infection, psoriatic arthritis, inflammatory bowel disease, malignancy, and aging. We present the JA in a rhupus patient with erosive and cystic changes in the hand joints. Although JA is considered a non-erosive arthropathy, it has been reported that erosions that can not be detected in direct radiography are revealed by imaging methods such as ultrasound, CT, and magnetic resonance imaging [2]. The effects of factors such as RF positivity, elevated acute phase reactants, disease duration, arthritis duration, and presence of anti-dsDNA antibodies have been shown in JA development [3]. It has been observed that patients with erosion tend to have a higher JA index score [4].
Sadettin Uslu

sadouslu@gmail.com

Tuba Yuce Inel

dr.tubayuce@yahoo.com

Çiğdem Samur Salbaş

drcigdemsamur@yahoo.com
1 Department of Rheumatology, Ömer Halisdemir University Bor Physical Medicine and Rehabilitation, Training and Research Hospital, Niğde, Turkey

2 Department of Rheumatology, Internal Medicine, Dokuz Eylül University School of Medicine, Izmir, Turkey

3 Department of Radiology, Ömer Halisdemir University School of Medicine, Training and Research Hospital, Niğde, Turkey 
Fig.1 a Photograph and b radiograph of both the hands of our patient showing flexion deformities at the metacarpophalangeal and distal interphalangeal joints and a hyperextension deformity at the proximal interphalangeal joints. c Coronal $\mathrm{CT}$ with bone window of the wrist demonstrates cortical erosions (arrow) and multiple subchondral degenerative cystic alterations of the carpal bones (arrowhead). Narrowing of the carpomatecarpal joints and sclerosis at joint surfaces are appreciable too

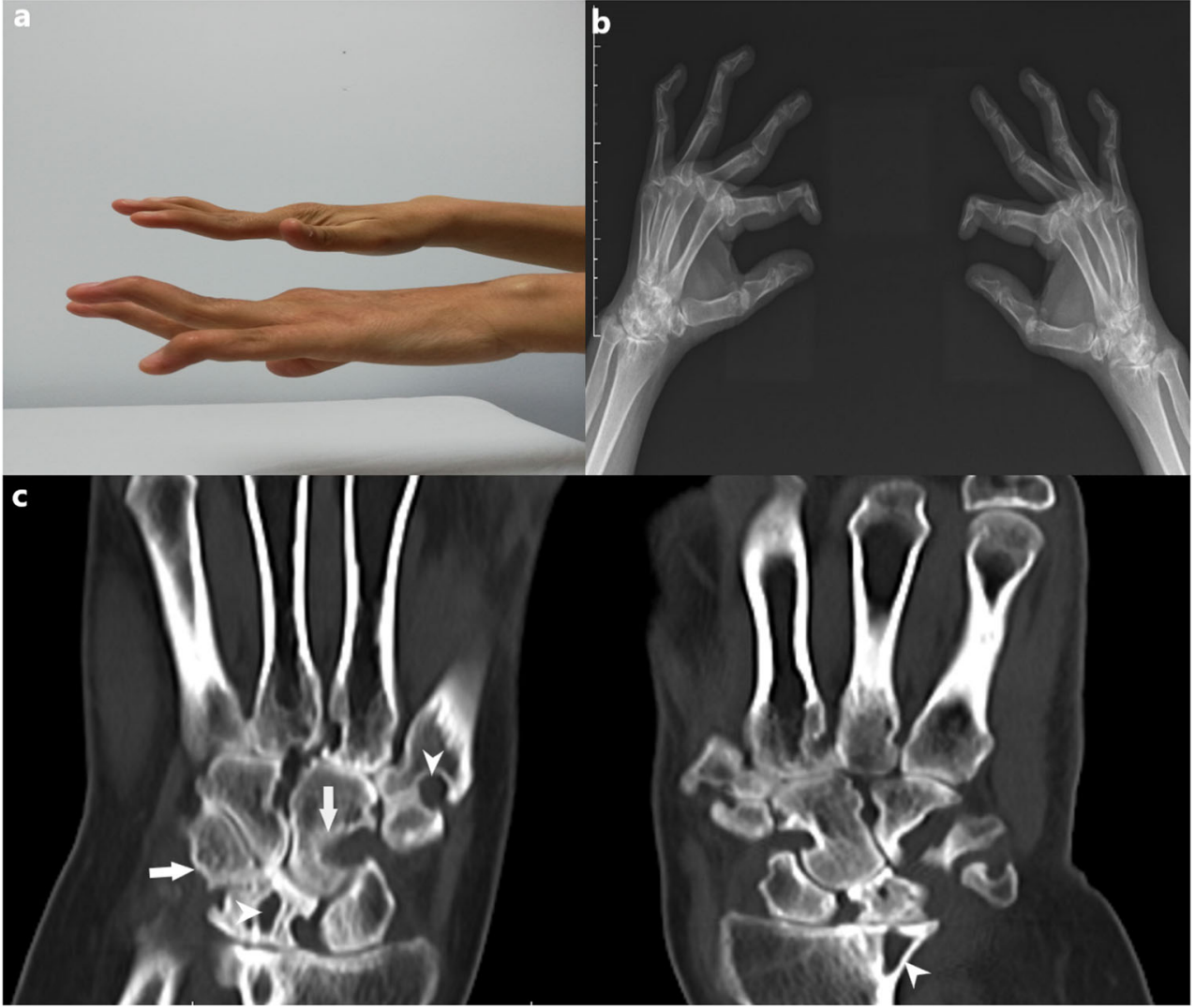

Author contributions All authors contributed to the literature search, analysis and/or interpretation, and design. The first draft of the manuscript was written by Sadettin Uslu and all the authors commented on previous versions of the manuscript. All authors read and approved the final manuscript.

\section{Compliance with ethical standards}

\section{Disclosures None.}

Informed consent We received informed consent from the patient for the publication of this case.

Ethics approval All procedures performed in this study were in accordance with the ethical standard of National Hospital Organization Okayama Medical Center and with the 1964 Helsinki declaration and its later amendments. IRB approval was waived.

Consent for publication We obtained written informed consent from the patient for publication of this case report together with any accompanying images.

\section{References}

1. Santiago MB (2011) Jaccoud's arthropathy. Best Pract Res Clin Rheumatol 25:715-725. https://doi.org/10.1016/j.berh.2011.10.018

2. Sá Ribeiro D, Galvão V, Luiz Fernandes J, de Araújo Neto C, D'Almeida F, Santiago M (2010) Magnetic resonance imaging of Jaccoud's arthropathy in systemic lupus erythematosus. Jt Bone Spine 77:241-245. https://doi.org/10.1016/j.jbspin.2009.10.013

3. Galvão V, Atta AM, Sousa Atta ML, Motta M, Dourado S, Grimaldi L, Oliveira e Silva N, Silva de Oliveira I, Santiago MB (2009) Profile of autoantibodies in Jaccoud's arthropathy. Jt Bone Spine 76:356360. https://doi.org/10.1016/j.jbspin.2008.11.003

4. Wright S, Filippucci E, Grassi W, Grey A, Bell A (2006) Hand arthritis in systemic lupus erythematosus: an ultrasound pictorial essay. Lupus 15:501-506. https://doi.org/10.1191/ 0961203306lu2340oa

Publisher's note Springer Nature remains neutral with regard to jurisdictional claims in published maps and institutional affiliations. 